\title{
In Vivo Morphology of the Limbal Palisades of Vogt Correlates With Progressive Stem Cell Deficiency in Aniridia-Related Keratopathy
}

Neil Lagali, Ulla Edén, Tor Paaske Utheim, Xiangjun Chen, Ruth Riise, Anette Delby and Per

Fagerholm

\section{Linköping University Post Print}

\section{Tweet}

N.B.: When citing this work, cite the original article.

Original Publication:

Neil Lagali, Ulla Edén, Tor Paaske Utheim, Xiangjun Chen, Ruth Riise, Anette Delby and Per Fagerholm, In Vivo Morphology of the Limbal Palisades of Vogt Correlates With Progressive Stem Cell Deficiency in Aniridia-Related Keratopathy, 2013, Investigative Ophthalmology and Visual Science, (54), 8, 5333-5342.

http://dx.doi.org/10.1167/iovs.13-11780

Copyright: Association for Research in Vision and Ophthalmology (ARVO) http://www.arvo.org/ 


\section{In vivo morphology of the limbal Palisades of Vogt correlates with progressive stem cell deficiency in aniridia-related keratopathy.}

Neil Lagali ${ }^{1}$, Ulla Edén ${ }^{1}$, Tor Paaske Utheim ${ }^{2,3}$, Xiangjun Chen ${ }^{4}$, Ruth Riise ${ }^{5}$, Anette Dellby $^{1}$, and Per Fagerholm ${ }^{1}$

${ }^{1}$ Department of Clinical and Experimental Medicine, Faculty of Health Sciences, Linköping University, Linköping, Sweden,

${ }^{2}$ Department of Medical Biochemistry, Oslo University Hospital, Oslo, Norway

${ }^{3}$ Schepens Eye Research Institute, Massachusetts Eye and Ear Infirmary, Harvard Medical School, Boston, MA, USA

${ }^{4}$ Synslaser Kirurgi AS, Oslo, Norway

${ }^{5}$ Department of Ophthalmology, Innland Hospital, Elverum, Norway

The authors wish to acknowledge financial contributions from Crown Princess Margareta's Foundation for the Visually Impaired, Carmen and Bertil Regnérs Foundation for Research in Eye Disease, the County Council of Östergötland, Konung Gustav V and Drottning Viktorias Frimurarestiftelse, The Swedish Research Council, and Aniridia Norway.

Abstract word count: 250

Word count: 4151

None of the authors have any proprietary/financial interest to disclose.

Address for Correspondence:

Neil Lagali, PhD

Dept of Ophthalmology

Institute for Clinical and Experimental Medicine

Faculty of Health Sciences

Linköping University

SE-581 83 Linköping

Sweden

Tel +46101034658

Fax +46101033065

Email neil.lagali@liu.se 


\begin{abstract}
Purpose: To investigate morphologic alterations in the limbal palisades of Vogt in a progressive form of limbal stem cell deficiency.

Methods: 20 Norwegian subjects (40 eyes) with congenital aniridia and 9 healthy family members (18 eyes) without aniridia were examined. Clinical grade of aniridia-related keratopathy (ARK) was assessed by slit lamp biomicroscopy, and tear production and quality, corneal thickness and sensitivity were additionally measured. The superior and inferior limbal palisades of Vogt and central cornea were examined by laser-scanning in vivo confocal microscopy (IVCM).
\end{abstract}

Results: In an aniridia patient with grade 0 ARK, a transparent cornea and normal limbal palisade morphology was found. In grade 1 ARK, 5/12 eyes had degraded palisade structures. In remaining grade 1 eyes and in all 20 eyes with stage 2, 3, and 4 ARK, palisade structures were absent by IVCM. Increasing ARK grade significantly correlated with reduced visual acuity and corneal sensitivity, increased corneal thickness, degree of degradation of superior and inferior Palisade structures, reduced peripheral nerves, increased inflammatory cell invasion, and reduced density of basal epithelial cells and central subbasal nerves. Moreover, limbal basal epithelial cell density and central corneal subbasal nerve density were both significantly reduced in aniridia compared to healthy corneas ( $\mathrm{P}=0.002$ and 0.003 , respectively).

Conclusions: Progression of limbal stem cell deficiency in aniridia correlates with degradation of palisade structures, gradual transformation of epithelial phenotype, onset of inflammation, and a corneal nerve deficit. IVCM can be useful in monitoring early to late-stage degenerative changes in stem cell deficient patients.

Key Words: limbal palisades of Vogt, corneal stem cells, corneal epithelium, subbsal nerves, aniridia, in vivo confocal microscopy, stem cell deficiency. 


\section{Introduction}

Aniridia is a rare congenital genetic disorder caused by a mutation in the Pax6 gene, often considered the 'master gene' for eye development. While absence of the iris is the hallmark feature of this disorder, corneal manifestations of aniridia include a thinned epithelium, thickened stroma, and a potentially blinding keratopathy. Aniridia-related keratopathy (ARK) is characterized by a progressive opacification of the cornea thought to result from a primary limbal stem cell deficiency. ${ }^{1}$ We recently published results from a study of a cohort of Swedish patients with congenital aniridia. ${ }^{2}$ In that study, laserscanning in vivo confocal microscopy (IVCM) of the cornea indicated a total loss of limbal palisades of Vogt in patients with ARK; however, in one patient, remnants of these structures were visible in a degenerated, altered form. This suggested the stem cell niche may not be absent in all cases. Additionally, alterations in subbasal nerves, epithelium, and dendritic immune cells were detected in patients.

Unlike many cases of clinical limbal stem cell deficiency, in which the normal structures of the limbal stem cell niche in affected regions are totally absent, ${ }^{3}$ a large group of aniridia patients can present a cross-section of progressive changes to the limbal stem cell environment. Moreover, in recent years laser-scanning IVCM has enabled a detailed morphologic picture of the limbal palisades of Vogt to be obtained, ${ }^{4-7}$ that could potentially improve our understanding of the exact location and function of the limbal stem cell niche, while aiding in the assessment, diagnosis, and monitoring of the status of the limbal stem cell niche in aniridia. In the present study, we investigated an aniridia cohort to document the clinical status of keratopathy and correlate these findings to morphological investigation of nerves, inflammatory cells, epithelium and structures of the limbal palisades of Vogt, the putative location for the limbal stem cell niche. Particular attention was given to the clinical stage of ARK, and whether clinical measures and the progressive opacification of the cornea in ARK correlated with the limbal morphology.

\section{Methods}

\section{Study subjects}


After obtaining ethical approval from the Regional Committee for Medical and Health Research Ethics in Oslo (Application No. 2011/2310/REK), and obtaining signed informed consent, 29 Norwegian subjects (58 eyes) were examined on a single occasion in Oslo. Of these, 20 were patients with aniridia, while the remaining subjects were 9 healthy accompanying relatives in good general health, without aniridia or other ocular pathology (control group). The study was conducted in accordance with the tenets of the Declaration of Helsinki.

\section{Clinical Examination}

Subjects underwent full clinical corneal examination bilaterally, and additional detailed examination by digital slit lamp photography and in vivo confocal microscopy (IVCM; Heidelberg Retinal Tomograph 3 with Rostock Cornea Module, Heidelberg Engineering, Germany). Slit lamp examination was conducted to assess the grade of ARK according to a previously published grading scale. ${ }^{2}$ Briefly, grade 0 corresponds to a totally clear cornea, initial peripheral vessel ingrowth occurs in grade 1, grade 2 is accompanied by conjunctivalization of the entire circumferential periphery, grade 3 is marked by central ingrowth of vessels with stromal involvement, and grade 4 is an opaque cornea.

Clinical examination included the following data or tests: status of Pax6 mutation (taken from patient records), best spectacle-corrected visual acuity (BSCVA), central corneal thickness measured by ultrasound pachymetry (TOMEY SP-2000), ocular surgery status (prior cataract or glaucoma surgery, taken from records), tear production by Schirmer's test without anaesthesia (normal tear secretion should moisten greater than $15 \mathrm{~mm}$ of the strip in five minutes, and $<5 \mathrm{~mm}$ is considered pathological), tear break-up time (BUT) to evaluate tear film stability (on the clear part of the cornea, with BUT $>10$ s regarded as normal), and corneal sensitivity by contact esthesiometry (Cochet-Bonnet esthesiometer, Luneau Ophthalmologie, France) where a nylon thread length of $60 \mathrm{~mm}$ was considered normal.

\section{In Vivo Confocal Microscopy}

IVCM was performed by a single operator in all subjects. Images of the superior and inferior limbus in the region of the palisades of Vogt were taken to document the status of the limbal stem cell niche. Additionally, where possible, images of the transition between 
limbal and corneal tissue at epithelial and subepithelial depth, and images of the central subbasal nerve plexus were acquired. During examination, the superior and inferior limbal regions and central cornea were accessed by instructing subjects to gaze into an external fixation target (diode lamp), which was manually adjusted until the central or limbal regions could be accessed. Subjects with very poor vision or those with difficulty in fixating were instructed to gaze straight forward, upwards, or downwards without use of the external target. Depth in the epithelium was first manually adjusted until the epithelial basal cell mosaic was visible, and then the microscopic field of view was manually translated inferiorly or superiorly, until the mosaic pattern was disrupted by the structures comprising the limbal palisades of $\mathrm{Vogt}^{2,4-7}$ or of conjunctival tissue. Lateral scanning of approximately 3 clock hours of limbus in superior and inferior regions was

performed. All subjects were non-pigmented. Images were acquired in real time, at a rate of 8 frames/sec for subjects in the control group, while the rate was increased to $15-20$ frames/sec in aniridia patients, to minimize image artifacts due to rapid eye movements (nystagmus). Images were acquired in the sequence scan mode of acquisition.

\section{IVCM image analysis}

All IVCM image data was saved with a unique numerical identifier. Images from each subject and eye were assessed by two independent observers masked to the subject name, gender, age, group identity (aniridia or control) and stage of ARK. For each eye, images (typically 1000 images or 10 scans per eye) were examined to determine the presence of the following 3 structures in the inferior and superior limbus, which when observed together (co-located across one or two IVCM image frames), were taken as positive evidence for the existence of a morphologically intact palisades of Vogt in a given limbal region:

1. Epithelial basal cells with dark cytoplasm and reflective cell borders.

2. At least two prominent palisade ridge structures.

3. At least one circular and/or oval-shaped focal stromal projections (FSPs) ${ }^{5}$

The presence or absence of intact palisades of Vogt was recorded for each eye, and in cases where the palisades were not observed, images were examined for the presence of 
recognizable palisade-like structures. Care was taken to ensure images were not oblique in the assessment, and structures were assessed at various depths to ensure ridges and/or FSPs did not merge into one structure, but were distinct structural entities.

Corneal epithelial morphology was assessed by the presence of basal epithelial cells with dark cytoplasm and distinct, bright borders in IVCM images, rendering the cell mosaic visible. Conjunctival epithelium by contrast, appears bright (highly light-scattering cytoplasm), cell borders and the mosaic are more difficult to discern, and goblet cells, cells with dendrites, and highly reflective, rounded leukocytic/inflammatory cells are typically found within the conjunctival epithelium. ${ }^{8,9}$

The presence of corneal subbasal nerves in the peripheral/limbal region was assessed based on the appearance of these nerves in IVCM images at the basal epithelial layer in the limbus or at the border of invading conjunctival tissue. Images of central corneal subbasal nerves were selected from central IVCM scans; images with clear, high-contrast nerves without obliqueness were chosen from a single eye per subject (right eye). In cases where several good-quality images with central subbasal nerves existed, a representative image was chosen for analysis. Central corneal subbasal nerve density was determined by a semi-automated tracing method as described previously ${ }^{2}$. Two independent and experienced observers masked to the patient identity traced nerves and recorded total nerve length in an IVCM image frame in $\mathrm{mm}$. From these values, average subbasal nerve density of both observers was determined and the mean value was reported in mm total nerve length per $\mathrm{mm}^{2}$ of area on the subbasal nerve plexus.

Epithelial cells in the limbal palisades region were analysed in the following manner, based on an earlier reported method. ${ }^{4}$ First, three clear images of limbal palisades and/or FSPs were chosen from one eye per subject. For healthy subjects, images were selected from the right eye, while images from aniridia patients were selected from a single eye based on the presence of full or partial palisade structures in that eye. Images were chosen where clearly visible epithelial basal cells and palisade ridges or FSPs were present (and in focus) in the same image frame. Images were then coded and randomized. In each masked image, ImageJ software (developed by Wayne Rasband, National Institutes of Health, Bethesda, MD; available at http://rsb.info.nih.gov/ij/index.html) was used to define a rectangular region of interest $(100 \times 50 \mu \mathrm{m}$, width $\times$ height or height $\times$ width). This rectangle was then placed over basal cells with clear boundaries in the 
vicinity of palisade ridges or FSPs. The area within the region of interest was then bandpass filtered in ImageJ, and the ImageJ 'Cell Counter' plugin was used to count the number of cells in the region, by marking each cell center by a mouse click. Cells touching the upper and right boundaries of the region were included, while those touching lower and left boundaries were excluded. Cell counting was done independently by two experienced observers. After cell counts were recorded, images were unmasked and the three cell counts were averaged and converted to cell density. Finally, cell density values from both observers were averaged, and the mean value reported.

\section{Quantitative and statistical analysis}

Inter-observer differences in quantification of subbasal nerve density and limbal epithelial cell density were assessed by the method of Bland and Altman. ${ }^{12}$ Inter-observer agreement was reported as the $95 \%$ limits of agreement (LOA). All statistics were performed with data from one eye per subject (right eye). Comparisons of epithelial cell density and subbasal nerve density between aniridia and healthy groups were made with the t-test where values were normally distributed, and with the Mann-Whitney Rank Sum test otherwise. Associations of clinical and IVCM parameters with ARK grade were tested with the Spearman Rank Order Correlation test. For BSCVA, Snellen values were first converted to logMAR scale. Ordinal scales were used for morphology of the limbal Palisades $(0=$ not present, $1=$ partially present, $2=$ fully present $)$, assessment of limbal nerves $(0=$ not present, $1=$ present $)$, and assessment of limbal inflammatory cells $(0=$ not present, $1=$ present). For all statistics, a two-tailed level of $\alpha=0.05$ was considered significant. All statistical tests were performed using commercial software (SigmaStat 3.5; Systat Software Inc., Chicago, IL).

\section{Results}

\section{Control group morphology}

Subjects in the control group had a mean age of 41 years (range $29-50$ years). Detailed slit lamp biomicroscopic observation revealed a normal-appearing cornea and limbal region in all controls, without visible pathology. Access to the superior and/or inferior 
limbal palisades region by IVCM was possible in 17 eyes of 9 subjects. In the remaining eye, excessive (voluntary) eye movement made it difficult to access the Palisades region. In all cases where it was possible to access the limbal Palisades, the presence or absence of morphologically normal Palisade ridges and FSPs in superior and inferior limbal locations was noted (Table 1).

Examples of the in vivo morphology of normal Palisade structures in the superior and inferior limbus are shown in Figure 1. Notably, the width of palisade ridges and FSPs and their relative abundance varied across subjects. In two control subjects, these differences were strikingly apparent. In one subject aged 44 years, ridges were short and wide and had approximately 5 to 10 wide FSPs present around each ridge, while in another subject aged 45 years, ridges were long and narrow, with about 1 small FSP present around each ridge (Figure 2).

In 5/17 eyes (29\%), a partial presence (defined as recognizable morphology but incomplete or abnormal in appearance) or total absence of at least one feature (Palisade ridges or FSPs) was noted (Figure 3, Table 1). In all cases, the inferior limbal Palisades were affected. Despite this, in all control subjects corneal epithelial basal cells had dark cytoplasm, distinct borders, and conjunctival morphology was absent within the cornea proper.

\section{Aniridia group morphology}

Of the 20 aniridia patients examined, the limbal region was visualized by IVCM in 18 patients (34 eyes). In the remaining cases, excessive nystagmus or patient noncompliance precluded IVCM examination of the limbus. The 18 patients had an average age of 33 years (range 16 - 62 years). The ARK severity grading ${ }^{2}$ for all examined eyes is given in Table 1.

In the single patient with grade 0 ARK bilaterally, a transparent cornea with intact limbal border was apparent on slit lamp examination (Figure 4). By IVCM, intact palisade structures were observed in superior and inferior locations in both eyes. The morphology of these structures appeared similar to those found in the control group.

Eyes with grade 1 ARK had a biomicroscopic appearance typical of early-stage keratopathy, with conjunctival tissue extending across the limbal barrier and into the 
peripheral cornea (Figure 5). In the 12 eyes with grade 1 ARK, no morphologically normal limbal palisade structures were observed by IVCM. In 5 eyes from 5 patients with grade 1 ARK, however, recognizable palisade-like features were observed in the limbus (Figure 5). These features, however, had a morphology that differed from the normal cornea or grade 0 ARK. Palisade ridges were no longer distinct, well-defined structures with high contrast relative to the surrounding cells, but instead appeared wider, less reflective, and with diminished contrast. Focal stromal projections also had reduced reflectivity and contrast with surrounding tissue, while the circular structure was incomplete or grossly enlarged. Epithelial basal cells had dark cytoplasm in some cases, while in other cases the regular basal cell mosaic was absent, and in other cases the cells appeared smaller with distinct nuclei and indistinct cell borders. Inflammatory and goblet cells were also observed.

In the remaining 7 eyes with grade $1 \mathrm{ARK}$, and in all eyes with grades 2, 3, and $4 \mathrm{ARK}$, no recognizable limbal palisade structures were observed in the superior or inferior limbal regions by IVCM. In eyes with grade 2 ARK, the limbal region consisted of tissue characteristic of a conjunctival phenotype. The limbal epithelium appeared opaque with blood vessels present, and the conjunctival border extended into the peripheral or midperipheral corrnea (Figure 6). The invading front was in some cases continuous, while in other cases, individual conjunctival cells or cell patches invaded the clear corneal epithelium, sometimes leaving 'holes' of clear corneal epithelium surrounded by conjunctival epithelium. Limbal cell invasion into the cornea was also observed, and cells of three distinct phenotypes were present (Figure 6): large round or oval-shaped cells with diffuse reflectivity (presumed goblet cells), smaller, round and highly reflective cells (presumed leukocytic inflammatory cells), and dendritic (Langerhans) cells. Dendritic cells, however, are normally resident in the peripheral cornea. ${ }^{10,11}$ Grades 3 and 4 had a similar conjunctival morphology that extended into the central cornea. When present, limbal or peripheral subbasal nerves did not appear to extend into the epithelium of conjunctival phenotype, but ran in a generally parallel direction to the invading front of conjunctival tissue (Figure 6). As previously reported in a cohort of Swedish aniridia patients, ${ }^{2}$ early opacification of the cornea occurred not only by the invasion of conjunctival tissue from the limbus, but also by development of isolated 'islands' of 
conjunctiva-like tissue present in the peripheral to mid-peripheral cornea. These islands were present at the lower wing to basal epithelial cell layers, and were also detected in the present Norwegian cohort. Islands were present in 12 of $24(50 \%)$ of non-vascularized eyes, predominantly in stage 1 and 2 ARK (Table 1), and were opaque with a characteristic conjunctival appearance (Figure 7).

\section{Quantitative analysis of clinical and IVCM parameters}

In Table 1, aniridia cohort data was arranged by increasing grade of ARK. Possible associations between grade of ARK and the various clinical and IVCM parameters were tested, with results given in Table 2. As severity of ARK increased, the following significant changes were noted: visual acuity worsened (increase in Snellen denominator), central corneal thickness increased, central corneal sensitivity decreased, superior and inferior palisade ridges and FSPs degraded, limbal nerves disappeared, inflammatory cells invaded the limbal region, epithelial basal cell density decreased in the Palisades region, and central subbasal nerve density declined. Age, tear production by the Schirmer test, and tear break up time did not correlate with grade of ARK. Comparison of the healthy versus the aniridia group revealed a significant reduction in basal epithelial cell density in aniridia (4344 \pm 749 cells $/ \mathrm{mm}^{2}$; mean \pm SD) versus healthy subjects $\left(5467 \pm 403\right.$ cells $/ \mathrm{mm}^{2} ; \mathrm{P}=0.002$, t-test). Likewise, subbasal nerve density in the central cornea was significantly reduced in aniridia $\left(9.1 \pm 8.1 \mathrm{~mm} / \mathrm{mm}^{2}\right)$ compared to healthy subjects $\left(18.3 \pm 3.7 \mathrm{~mm} / \mathrm{mm}^{2} ; \mathrm{P}=0.003\right.$, Mann-Whitney Rank Sum test $)$. The 95\% LOA for inter-observer differences in density measurement were \pm 1947 cells $/ \mathrm{mm}^{2}$ for epithelial cells and $\pm 7.0 \mathrm{~mm} / \mathrm{mm}^{2}$ for subbasal nerves.

\section{Discussion}

In this study, strong correlations were found between in vivo morphology of the limbal stem cell niche, limbal epithelium and nerves, inflammation, and the stage of progressive corneal opacification in ARK. These findings provide a detailed description of the pathogenesis of ARK. In early stages, the cornea may have functioning stem cells and intact limbal border, as demonstrated by the single case of grade 0 ARK with intact limbal palisade morphology. Although onset of ARK typically occurs during the first decade of life, ${ }^{1,8}$ the case of grade 0 ARK occurred in a subject aged 54 years, 
highlighting the variability in progression of ARK. In general, age was a poor predictor of grade of ARK, in contrast to our earlier cohort ${ }^{2}$ where only subjects with grade 1 and 2 ARK were compared.

The following picture of the pathogenesis of ARK emerges from this study. In the early stage of grade 0 ARK, corneal and conjunctival epithelium have a defined border, basal epithelial cells near Palisade ridges have clear cell borders, dark cytoplasm and a normal density, and corneal nerves are unaffected. Clinical features such as central corneal thickness and touch sensitivity are normal. As the stem cell deficiency progresses, the limbal barrier is breached, and grade 1 ARK ensues. In this stage, structures of the limbal palisades appear in a substantially degraded form or may be totally absent. In cases with partially present palisade morphology, the following features are noted: short, shallow palisade ridges, breakdown of FSPs, loss of visible underlying blood vessels, and loss of the corneal basal cell mosaic. Concomitantly, basal cells increase in size and single conjunctival epithelial cells or larger islands of conjunctival tissue (with light-scattering cytoplasm) establish in the peripheral cornea. Peripheral and central subbasal nerves are largely unaffected in grade 1 ARK, although some reduction in corneal touch sensitivity may be apparent. Central corneal thickness increases ${ }^{13,14}$ at this early stage, regardless of whether intraocular surgery has been performed. In grade $2 \mathrm{ARK}$, palisade structures are no longer present, inflammatory and goblet cells invade the limbus and peripheral cornea, and conjunctival tissue further encroaches into the cornea. An early loss of limbal/peripheral nerves is apparent in some cases, and central subbasal nerve density starts to decline. Central corneal thickness is still similar to grade 1 ARK. Finally in grades 3 and 4 ARK, conjunctival tissue, blood vessels, goblet and inflammatory cells invade the central cornea, peripheral and central subbasal nerves are lost, the cornea further increases in thickness, and touch sensitivity is reduced.

This picture of the progression of ARK suggests a close relationship between structure of the limbal palisade ridges/FSPs and the eventual fate of corneal epithelial cells and subbasal nerves. Peripheral epithelium and nerves are impacted first, and in later stages central epithelium and nerves are affected. Peripheral epithelial cells and subbasal nerves migrate to the central cornea by centripetal cell movement ${ }^{15}$ and centripetal nerve growth, ${ }^{16,17}$ and in a previous study of aniridia patients, evidence of the close correlation of centripetal cell and nerve migration was presented. ${ }^{2}$ Observations of peripheral corneal 
nerve changes preceding the central loss of subbasal nerves (and ocular surface sensitivity) provides further evidence of the close association of corneal epithelium and subbasal nerves. Although the opaque conjunctival epithelium may have obscured detection of subbasal nerves by IVCM, ${ }^{3}$ results in this study suggest that even where subbasal nerves may be present under conjunctivalized epithelium, their connections to nerve endings at the superficial epithelium are disrupted, resulting in reduced ocular surface sensitivity.

The IVCM findings in this study are relevant in the context of recent reports describing the limbal morphology in normal eyes and those with partial or total limbal stem cell deficiency. ${ }^{3,4}$ In those studies, the normal density of basal epithelial cells in the palisade region was in close agreement with values reported in this study, ${ }^{4}$ and a marked decline in basal cell density was noted in patients with limbal stem cell deficiency of varying etiology. ${ }^{3,18}$ Likewise, mean subbasal nerve density in cases of partial limbal stem cell deficiency in one study ${ }^{3}\left(9.70 \pm 6.32 \mathrm{~mm} / \mathrm{mm}^{2}\right)$ was close to the mean value in the present aniridia cohort $\left(9.1 \pm 8.1 \mathrm{~mm} / \mathrm{mm}^{2}\right)$, and in another study, increasing severity of limbal stem cell deficiency correlated with a decline in central subbasal nerve density. ${ }^{18}$ We note however, a wide variability in subbasal nerve density in aniridia patients, with some corneas with grade 1 or 2 ARK exhibiting normal or supra-normal density values. In an earlier study of a Swedish aniridia cohort, we reported an unusually high nerve density in several cases, which was thought to relate to epithelial pathology in aniridia. ${ }^{2}$ Such high nerve densities, however, were not included in the analysis of the present Norwegian cohort; instead, representative images of subbasal nerves were chosen to reflect the overall condition of the subbasal nerve plexus, whereas only the highest density region was selected in the prior study. In both cohorts, however, the range of nerve density was large, with some patients having a density below $5 \mathrm{~mm} / \mathrm{mm}^{2}$ in grade 1 or 2 ARK. Our findings of significantly reduced density in the Norwegian cohort extend findings of reduced epithelial innervation in Pax6 heterozygous mice ${ }^{19}$ to human subjects.

Another notable finding in this study was a large degree of variation in palisade morphology in normal subjects of homogeneous pigmentation. Differences in the size and relative abundance of palisade ridges and FSPs were apparent. Variation in the limbal palisade morphology may represent varying levels of redundancy of the stem cell niche, 
and may arise from genetic or environmental factors. Despite this variation, however, several studies (including the present study) have revealed a population of healthy controls in whom the limbal palisades are either absent or present in a partial, degraded form. $^{4,20,21}$ In the present study, 3 of 9 control subjects had missing or partially present palisade ridges or FSPs. All abnormal findings in control eyes were present in the inferior limbus in this study in subjects aged 38 to 48 years, and similarly occurred in older subjects in the inferior limbus in the studies by Patel et al. ${ }^{4}$ and Zheng et al. ${ }^{20}$ The upper eyelid presumably protects the superior limbal palisades from degradation in the normal cornea in a proportion of older subjects. This hypothesis is consistent with recent laboratory studies demonstrating the highest colony-forming efficiency from biopsies of the superior and inferior limbal regions, ${ }^{5,22}$ while the superior limbal region in particular has been shown to yield the highest epithelial cell thickness of cultured limbal explants. ${ }^{23}$

Although gaps exist in our understanding of the relationship between structure and function of the limbal epithelial stem cell niche, IVCM is an advantageous technique for investigations into this relationship. A strong correlation between palisades of Vogt morphology and severity of keratopathy was present in this study, further supporting the hypothesis of the limbal location of corneal epithelial stem cells ${ }^{24}$ and their colocation with the palisades of Vogt. A strong correlation of the grade of stem cell deficiency with epithelial basal cells and corneal subbasal nerves was also evident. This study indicates the potential for IVCM to be used as an aid in the diagnosis ${ }^{25}$ and monitoring of progressive stem cell deficiency. Specifically, in suspected stem cell deficiency at an early stage, pathological changes to the limbal border and palisades of Vogt may not be easy to visualize by slit lamp biomicroscopy, ${ }^{3}$ especially in non-pigmented subjects. By contrast, degradation of the palisades of Vogt and FSPs at an early stage is dramatic in IVCM images. In a progressing stage, inflammatory and goblet cells invading the peripheral cornea are easily visualized by IVCM, whereas these cells cannot be seen with the slit lamp or other non-invasive techniques. Finally, peripheral and central corneal nerves can be visualized and quantified to gauge the degree of pathology in later stages. When combined, these IVCM measures can be more sensitive and specific indicators of keratopathy progression in stem cell deficient eyes than clinical photography or 
measurement of tears, touch sensitivity, and corneal thickness, which can have a wide range of values in both healthy and pathologic corneas.

\section{Acknowledgements}

The authors would like to thank Johan Germundsson MD, for assistance with cell and nerve density quantification, and Trond Leren of the Department of Medical Genetics in Oslo University Hospital, for the Pax6 genetic analysis.

\section{References}

1. Ramaesh K, Ramaesh T, Dutton GN, Dhillon B. Evolving concepts on the pathogenic mechanisms of aniridia related keratopathy. Int J Biochem Cell Biol 2005;37:547557.

2. Edén U, Fagerholm P, Danyali R, Lagali N. Pathologic epithelial and anterior corneal nerve morphology in early-stage congenital aniridic keratopathy. Ophthalmology 2012;119:1803-10.

3. Miri A, Alomar T, Nubile M, et al. In vivo confocal microscopic findings in patients with limbal stem cell deficiency. Br J Ophthalmol 2012;96:523-529.

4. Patel DV, Sherwin T, McGhee CN. Laser scanning in vivo confocal microscopy of the normal human corneoscleral limbus. Invest Ophthalmol Vis Sci 2006;47:2823-7.

5. Shortt AJ, Secker GA, Munro PM, et al. Characterization of the limbal epithelial stem cell niche: novel imaging techniques permit in vivo observation and targeted biopsy of limbal epithelial stem cells. Stem Cells 2007;25:1402-9.

6. Takahashi N, Chikama T, Yanai R, Nishida T. Structures of the corneal limbus detected by laser-scanning confocal biomicroscopy as related to the palisades of Vogt detected by slit lamp microscopy. Jpn J Ophthalmol 2009;53:199-203.

7. Miri A, Al-Aqaba M, Otri AM, et al. In vivo confocal microscopic features of normal limbus. Br J Ophthalmol 2012;96:530-536.

8. Messmer EM, Mackert MJ, Zapp DM, Kampik A. In vivo confocal microscopy of normal conjunctiva and conjunctivitis. Cornea 2006;25:781-788. 
9. Zhivov A, Stachs O, Kraak R, Stave J, Guthoff RF. In vivo confocal microscopy of the ocular surface. Ocul Surf 2006;4:81-93.

10. Zhivov A, Stave J, Vollmar B, Guthoff R. In vivo confocal microscopic evaluation of Langerhans cell density and distribution in the normal human corneal epithelium. Graefe's Arch Clin Exp Ophthalmol 2005;243:1056-1061.

11. Zhivov A, Stave J, Vollmar B, Guthoff R. In vivo confocal microscopic evaluation of Langerhans cell density and distribution in the corneal epithelium of healthy volunteers and contact lens wearers. Cornea 2007;26:47-54.

12. Bland JM, Altman DG. Statistical methods for assessing agreement between two methods of clinical measurement. Lancet 1986;1:307-310.

13. Brandt JD, Casuso LA, Budenz DL. Markedly increased central corneal thickness: an unrecognized finding in congenital aniridia. Am J Ophthalmol 2004;137:348-350.

14. Whitson JT, Liang C, Godfrey DG et al. Central corneal thickness in patients with congenital aniridia. Eye Cont Lens 2005;31:221-224.

15. Collinson JM, Chanas SA, Hill RE, West JD. Corneal development, limbal stem cell function, and corneal epithelial cell migration in the $\mathrm{Pax} 6^{+/-}$mouse. Invest Ophthalmol Vis Sci 2004;45:1101-1108.

16. Patel DV, McGhee CNJ. In vivo laser scanning confocal microscopy confirms that the human corneal sub-basal nerve plexus is a highly dynamic structure. Invest Ophthalmol Vis Sci 2008;49:3409-3412.

17. Marfurt CF, Cox J, Deek S, Dvorscak L. Anatomy of the human corneal innervation. Exp Eye Res 2010;90:478-492.

18. Deng SX, Sejpal KD, Tang Q, Aldave AJ, Lee OL, Yu F. Characterization of limbal stem cell deficiency by in vivo laser scanning confocal microscopy: a microstructural approach. Arch Ophthalmol. 2012;130:440-5.

19. Leiper LJ, Ou J, Walczysko P, Kucerova R, Lavery DN, West JD, Collinson JM. Control of patterns of corneal innervation by Pax6. Invest Ophthalmol Vis Sci 2009;50:1122-1128.

20. Zheng T, Xu J. Age-related changes of human limbus on in vivo confocal microscopy. Cornea 2008;27:782-786.

21. Townsend WM. The limbal palisades of Vogt. Trans Am Ophthalmol Soc 1991;89:721-756. 
22. Meyer-Blazejewska EA, Kruse FE, Bitterer K et al. Preservation of the limbal stem cell phenotype by appropriate culture techniques. Invest Ophthalmol Vis Sci 2010; 51:765-774.

23. Utheim TP, Raeder S, Olstad OK et al. Comparison of the histology, gene expression profile, and phenotype of cultured human limbal epithelial cells from different limbal regions. Invest Ophthalmol Vis Sci 2009; 50:5165-5172.

24. Schermer A, Galvin S, Sun TT. Differentiation-related expression of a major $64 \mathrm{~K}$ corneal keratin in vivo and in culture suggests limbal location of corneal epithelial stem cells. J Cell Biol 1986;103:49-62.

25. Nubile M, Lanzini M, Miri A, et al. In vivo confocal microscopy in diagnosis of limbal stem cell deficiency. Am J Ophthalmol 2013;155:220-232. 
Figure Legends

Figure 1. Characteristic limbal Palisade ridges (white arrows) and FSPs (black arrows) observed in the inferior and superior limbal regions in controls. A varied morphological appearance of ridges (width and reflectivity) and FSPs (size, circularity, and location between or distal to adjacent ridges) was observed. Note the well-defined cell borders and dark cytoplasm of epithelial basal cells (asterisks). All images are $400 \times 400 \mu \mathrm{m}$.

Figure 2. Varied in vivo appearance of limbal Palisade ridges and FSPs in the superior cornea of two non-pigmented control subjects. (A) wide, short ridges and large, denselydistributed FSPs, with approximately 5-10 FSPs/ridge. (B) narrow, long ridges and sparse, small FSPs (arrows), with approximately 1 FSP/ridge. Images are at the same scale, $400 \times 400 \mu \mathrm{m}$ (width $\times$ height).

Figure 3. Incomplete or absent structures in the inferior limbal palisades region in control subjects. (A, B) from Subject 2, 48 years old, (C, D) from Subject 3, 44 years old, (E, F) from Subject 4, 38 years old. (A) Shallow palisade ridge remnants (arrows) present only in the basal epithelial cell layer, and not in overlying wing cell layers. (B) Short, shallow, indistinct stubs (arrows) replace normal palisade ridges. A horizontal ridge-like structure (arrowheads) with underlying blood vessel appears to connect ridges. (C) Short ridges with blood vessels visible (arrows), connected by horizontal ridge-like structures (arrowheads). (D) Short, shallow ridge-like stubs (arrows) and more prominent FSP (arrowhead). (E) Absence of FSPs in the right eye, with the distal end of palisade ridges terminating at the typical 'cracked' appearance of the epithelium in the corneal limbus region (arrowheads). ${ }^{4,7}$ Palisade ridges normally terminate substantially further from the region of cracked epithelium ${ }^{4,7}$ - see for example Figure 2A. (F) Absence of FSPs in the left eye. All images are $400 \times 400 \mu \mathrm{m}$.

Figure 4. Appearance of the cornea in a 54 year old male aniridia patient with grade 0 ARK. Top, left: slit lamp biomicroscope appearance of the cornea indicating a transparent cornea with no visible iris. Top, right: enlarged view of limbal region indicating a well-defined limbal border where conjunctival tissue and vessels are confined to the limbus and do not enter the cornea. Bottom: Corresponding IVCM 
appearance of limbal palisades. Distinct palisade ridges, focal stromal projections, and basal cells with distinct borders were visible in both eyes in superior and inferior locations. Approximately $1 \mathrm{FSP} /$ ridge was observed. Morphology of the palisade structures resembled that of healthy controls. Images are $400 \times 400 \mu \mathrm{m}$.

Figure 5. Limbal appearance in aniridia patients with grade 1 ARK. (A) A tongue of conjunctival tissue extends over the limbal border in one patient. (B) In another patient, a front of conjunctival tissue (arrows) in an early phase of peripheral corneal invasion. (C H) IVCM appearance of limbal Palisade-like structures in five patients with stage 1 ARK. (C) Ridge-like structures (white arrows) appear wide and with reduced contrast. Epithelial cells exhibit reflective nuclei (white arrowheads) while cell borders were difficult to discern. Note the additional presence of goblet cells (black arrows). (D) Ridge structures (arrows) with presumed inflammatory cells in close proximity. Note the absence of a well-defined epithelial cell mosaic. (E) Shortened palisade ridges (arrows) with reduced contrast and ill-defined borders. (F) Indistinct ridges (arrows) and loss of bright, distinctive basal cell borders. (G) Enlarged focal stromal projection (arrow). (H) Focal stromal projections with incomplete circular arrangement of cells (arrows). In all cases, images with the most clearly visible structures were chosen. At other depths, the structures had poorer contrast and visibility. Images are $400 \times 400 \mu \mathrm{m}$.

Figure 6. Morphologic features of limbal and peripheral cornea in ARK. Stage of ARK is given in the top right corner of each image. (A, B) Subbasal nerves were visible (white arrows) at the border of the invading front of conjunctival tissue in milder stages of ARK. Conjunctival tissue also contained blood vessels (B, black arrow). (C) Early invasion of epithelium by conjunctival tissue, with individual conjunctival cells (arrows) seen entering the cornea. (D) Invading conjunctival tissue has an uneven border, with small patches of conjunctiva visible in the corneal epithelium (white arrows). Presumed goblet cells are also visible (black arrows). Invading conjunctiva sometimes left 'holes' of corneal epithelium (asterisk). (E) Suspected inflammatory (black arrows) and goblet (white arrows) cells infiltrating the peripheral cornea. (F) Massive influx of inflammatory cells invading the mid-peripheral cornea. (G) Slit lamp photograph of invading front of 
conjunctiva (arrows) in a patient with grade 2 ARK. The central cornea is transparent. Images (A-F) are $400 \times 400 \mu \mathrm{m}$.

Figure 7. Islands of conjunctival tissue that have invaded the transparent corneal epithelium in four patients with stage 1 or 2 ARK. (A, C, D) Stage 1 ARK, and (B) Stage 2 ARK. Note the absence of clearly-delineated basal cell borders, and the visibility of basal cell nuclei (arrows). All images are $400 \times 400 \mu \mathrm{m}$. 


\section{inferior}

limbus

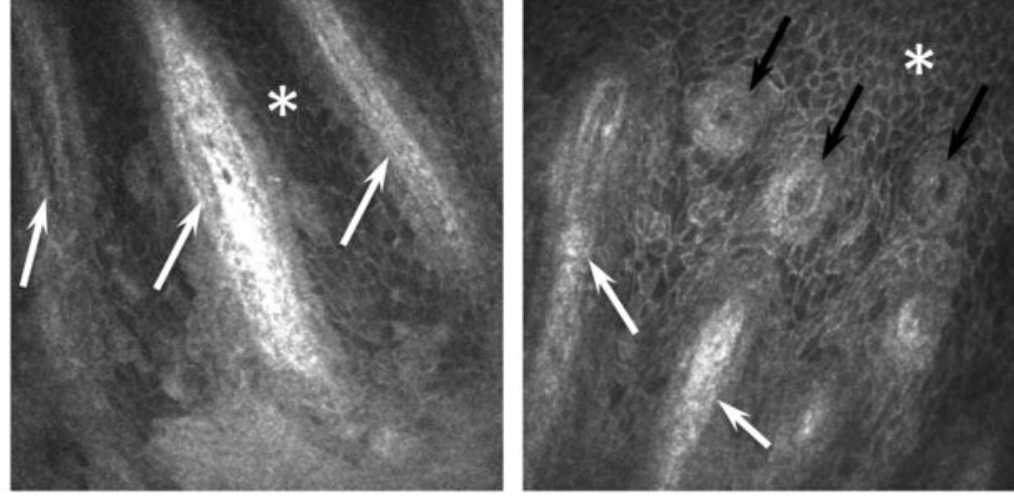

superior limbus
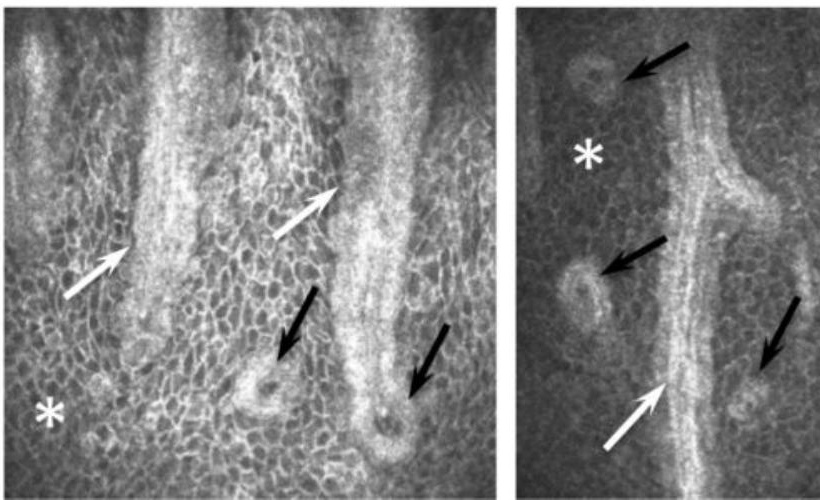

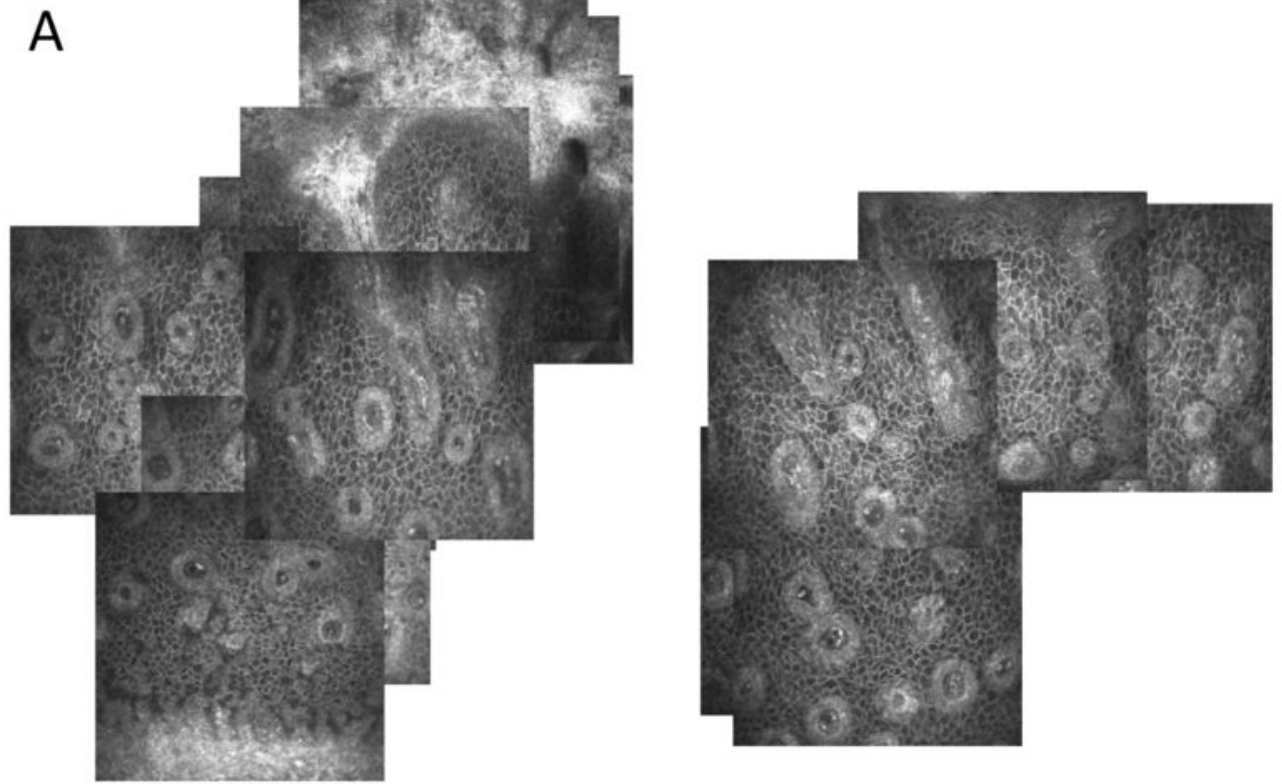

B

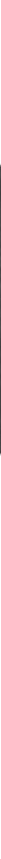




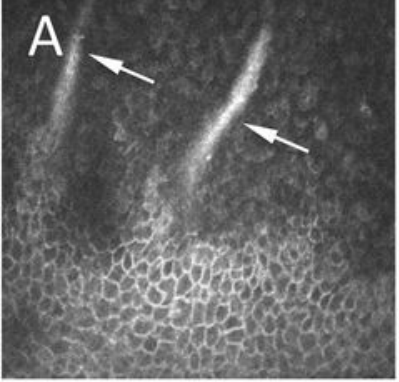

B

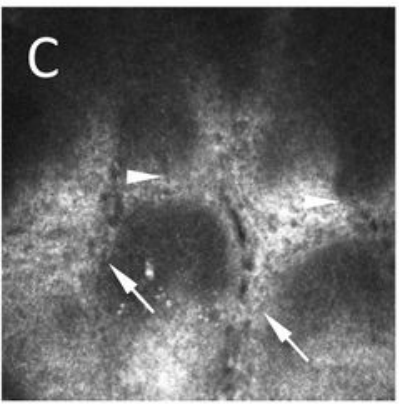

D
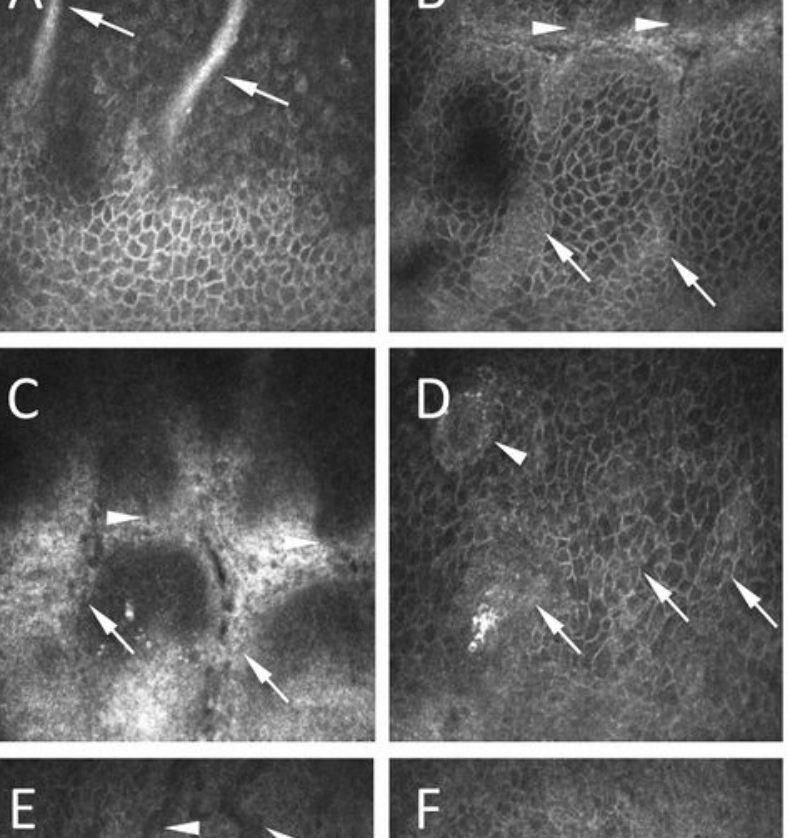

F

Hen 180

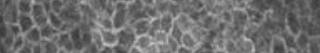
3.

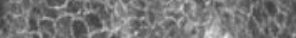
Whase 


\section{OS}

superior limbus

inferior limbus
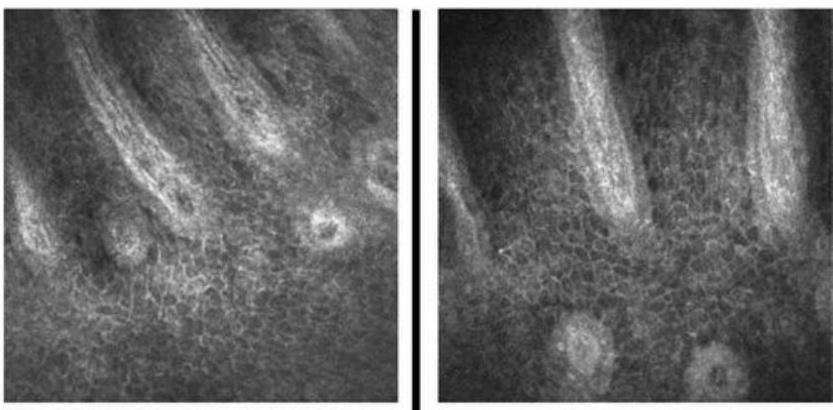


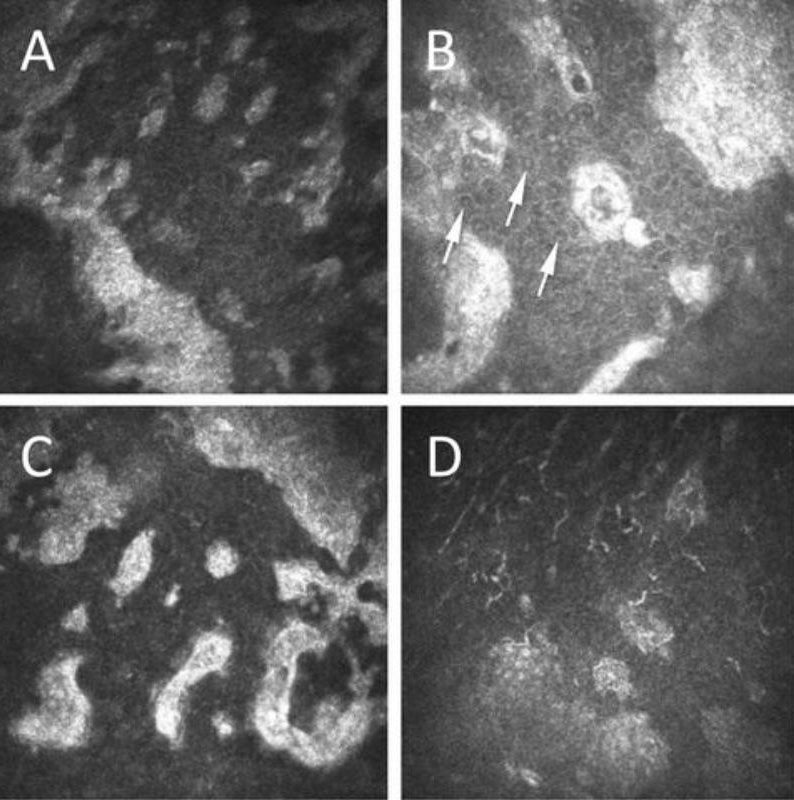


Clinical Measures

IVCM Parameters

\begin{tabular}{|c|c|c|c|c|c|c|c|c|c|c|c|c|c|c|c|c|c|c|c|c|}
\hline \multirow{4}{*}{$\begin{array}{l}\text { Subject } \\
\text { Aniridia }\end{array}$} & \multirow{3}{*}{$\begin{array}{l}\text { Age } \\
\text { (y) }\end{array}$} & \multirow{3}{*}{ Eye } & & & & & & & & & & \\
\hline & & & \multirow{3}{*}{$\begin{array}{l}\text { ARK } \\
\text { Grade }\end{array}$} & \multirow[t]{3}{*}{ Pax6 muation } & \multirow{3}{*}{$\begin{array}{c}\text { BSCVA } \\
(20 /)\end{array}$} & \multirow{3}{*}{$\begin{array}{l}\text { CCT } \\
(\mu \mathrm{m})\end{array}$} & \multicolumn{2}{|c|}{ Surgeries } & \multirow{3}{*}{$\begin{array}{l}\text { Schirmer } \\
(\mathrm{mm})\end{array}$} & \multirow{3}{*}{$\begin{array}{l}\text { BUT } \\
(\mathrm{s})\end{array}$} & \multirow{3}{*}{$\begin{array}{l}\text { Sensitivity } \\
(\mathrm{mm})\end{array}$} & \multicolumn{2}{|c|}{$\begin{array}{l}\text { Superior } \\
\text { Limbus }\end{array}$} & \multicolumn{2}{|c|}{$\begin{array}{l}\text { Inferior } \\
\text { Limbus }\end{array}$} & \multirow{3}{*}{$\begin{array}{l}\text { Conjunctival } \\
\text { Islands }\end{array}$} & \multirow{3}{*}{$\begin{array}{c}\text { Limbal/ } \\
\text { peripheral } \\
\text { nerves }\end{array}$} & \multirow{3}{*}{$\begin{array}{l}\text { Limbal } \\
\text { infl } \\
\text { cells }\end{array}$} & \multirow{3}{*}{$\begin{array}{l}\text { Basal cell } \\
\text { density } \\
\text { cells } / \mathrm{mm}^{2}\end{array}$} & $\begin{array}{c}\text { Subbasal nerve } \\
\text { density }\end{array}$ \\
\hline & & & & & & & Cataract & Glaucoma & & & & Ridges & FSP & Ridges & FSP & & & & & $\left(\mathrm{mm} / \mathrm{mm}^{2}\right)$ \\
\hline & & & & & & & & & & & & & & & & & & & & \\
\hline 1 & 54 & OD & 0 & $\mathrm{NF}$ & 200 & 586 & Y & $\mathrm{Y}$ & 14 & 7 & 60 & Full & Full & Full & Full & $\mathrm{N}$ & $\mathrm{Y}$ & $\mathrm{N}$ & 5500 & 15.1 \\
\hline & & OS & 0 & & 35 & 579 & Y & Y & 17 & 6 & 60 & Full & Full & Full & Full & $\mathrm{N}$ & Y & $\mathrm{N}$ & & \\
\hline 2 & 37 & OD & 1 & G51X exon 6 & 200 & 606 & Y & Y & 16 & 14 & 60 & $\mathrm{~N}$ & $\mathrm{~N}$ & $\mathrm{~N}$ & $\mathrm{~N}$ & Y & Y & Y & & 9.3 \\
\hline & & OS & 1 & & 500 & 541 & Y & $\mathrm{Y}$ & 35 & 4 & 50 & $\mathrm{~N}$ & $\mathrm{~N}$ & Partial & Partial & Y & Y & Y & 4900 & \\
\hline 3 & 25 & OD & 1 & ND & 2000 & 752 & Y & $\mathrm{Y}$ & 13 & 18 & 50 & $\mathrm{~N}$ & $\mathrm{~N}$ & $\mathrm{~N}$ & $\mathrm{~N}$ & $\mathrm{~N}$ & Y & $\mathrm{N}$ & & 11.5 \\
\hline & & OS & 1 & & 4000 & 978 & Y & Y & 19 & 3 & 35 & $\mathrm{~N}$ & $\mathrm{~N}$ & $\mathrm{~N}$ & $\mathrm{~N}$ & $\mathrm{~N}$ & Y & $\mathrm{N}$ & & \\
\hline 4 & 18 & OD & 1 & C40 exon 5 & 200 & 639 & & & 35 & - & 50 & $\mathrm{~N}$ & $\mathrm{~N}$ & $\mathrm{~N}$ & $\mathrm{~N}$ & Y & Y & $\mathrm{N}$ & & 15.2 \\
\hline & & OS & 1 & & 125 & 615 & & & 35 & 1 & 60 & - & - & - & - & - & Y & $\mathrm{N}$ & & \\
\hline 5 & 16 & OD & 1 & $1545+5 \mathrm{G}>\mathrm{A}$ & 50 & 691 & Y & $\mathrm{Y}$ & 35 & 24 & 60 & $\mathrm{~N}$ & $\mathrm{~N}$ & Partial & Partial & Y & Y & $\mathrm{N}$ & 3600 & 17.0 \\
\hline & & OS & 1 & & 70 & 601 & Y & Y & 35 & 24 & 60 & $\mathrm{~N}$ & $\mathrm{~N}$ & $\mathrm{~N}$ & $\mathrm{~N}$ & Y & Y & $\mathrm{N}$ & & \\
\hline 6 & 45 & OD & 1 & ND & 25 & 548 & Y & & 4 & 6 & 60 & $\mathrm{~N}$ & $\mathrm{~N}$ & $\mathrm{~N}$ & $\mathrm{~N}$ & $\mathrm{Y}$ & Y & $\mathrm{N}$ & & 17.5 \\
\hline & & OS & 1 & & 25 & 547 & Y & & 12 & 7 & 60 & - & - & Partial & $\mathrm{N}$ & Y & Y & $\mathrm{N}$ & 4433 & \\
\hline 7 & 36 & OD & 1 & R203X exon 8 & 125 & 617 & & Y & 25 & 15 & 60 & $\mathrm{~N}$ & $\mathrm{~N}$ & Partial & $\mathrm{N}$ & Y & Y & Y & 3667 & 17.9 \\
\hline & & OS & 1 & & 125 & 610 & & $\mathrm{Y}$ & 28 & 18 & 60 & $\mathrm{~N}$ & $\mathrm{~N}$ & $\mathrm{~N}$ & $\mathrm{~N}$ & $\mathrm{~N}$ & Y & $\mathrm{N}$ & & \\
\hline 8 & 19 & OD & 1 & ND & 200 & 618 & & & 35 & 8 & 60 & $\mathrm{~N}$ & $\mathrm{~N}$ & Partial & $\mathrm{N}$ & $\mathrm{N}$ & Y & Y & 3967 & 17.3 \\
\hline & & OS & 1 & & 100 & 617 & & & 35 & 7 & 60 & $\mathrm{~N}$ & $\mathrm{~N}$ & $\mathrm{~N}$ & $\mathrm{~N}$ & Y & Y & $\mathrm{N}$ & & \\
\hline 9 & 16 & $\mathrm{OD}$ & 2 & 900delCexon 8 & 200 & 555 & Y & $\mathrm{Y}$ & 35 & 13 & 60 & $\mathrm{~N}$ & $\mathrm{~N}$ & $\mathrm{~N}$ & $\mathrm{~N}$ & Y & Y & Y & & 3.7 \\
\hline & & OS & 2 & & 200 & 616 & Y & Y & 28 & 9 & 60 & $\mathrm{~N}$ & $\mathrm{~N}$ & $\mathrm{~N}$ & $\mathrm{~N}$ & $\mathrm{Y}$ & Y & $\mathrm{Y}$ & & \\
\hline 10 & 19 & OD & 2 & ND & 100 & 616 & & & 12 & 15 & 60 & $\mathrm{~N}$ & $\mathrm{~N}$ & $\mathrm{~N}$ & $\mathrm{~N}$ & $\mathrm{~N}$ & Y & Y & & 15.0 \\
\hline & & OS & 2 & & 125 & 619 & & & 14 & 10 & 55 & $\mathrm{~N}$ & $\mathrm{~N}$ & $\mathrm{~N}$ & $\mathrm{~N}$ & $\mathrm{~N}$ & $\mathrm{~N}$ & Y & & \\
\hline 11 & 28 & OD & 2 & ND & 125 & 616 & & & 24 & 5 & 60 & $\mathrm{~N}$ & $\mathrm{~N}$ & $\mathrm{~N}$ & $\mathrm{~N}$ & $\mathrm{~N}$ & Y & Y & & 24.9 \\
\hline & & OS & 2 & & 200 & 604 & & & 30 & 4 & 60 & $\mathrm{~N}$ & $\mathrm{~N}$ & $\mathrm{~N}$ & $\mathrm{~N}$ & $\mathrm{~N}$ & $\mathrm{Y}$ & Y & & \\
\hline 12 & 19 & OD & 2 & $\mathrm{NF}$ & 2000 & 623 & & Y & 35 & 16 & 60 & - & - & - & - & $\mathrm{N}$ & - & $\mathrm{Y}$ & & 10.9 \\
\hline & & OS & 2 & & 50 & 632 & & $\mathrm{Y}$ & 28 & 20 & 60 & $\mathrm{~N}$ & $\mathrm{~N}$ & $\mathrm{~N}$ & $\mathrm{~N}$ & $\mathrm{~N}$ & $\mathrm{~N}$ & $\mathrm{Y}$ & & \\
\hline 13 & 52 & OD & 3 & 900delCexon 8 & 200 & 662 & & & - & - & - & $\mathrm{N}$ & $\mathrm{N}$ & $\mathrm{N}$ & $\mathrm{N}$ & vascularized & $\mathrm{N}$ & Y & & 0,0 \\
\hline & & OS & 3 & & 400 & 694 & & & - & - & - & $\mathrm{N}$ & $\mathrm{N}$ & $\mathrm{N}$ & $\mathrm{N}$ & vascularized & $\mathrm{N}$ & Y & & \\
\hline 14 & 54 & OD & 3 & $\mathrm{NF}$ & 2000 & 541 & & Y & 27 & - & 60 & $\mathrm{~N}$ & $\mathrm{~N}$ & $\mathrm{~N}$ & $\mathrm{~N}$ & $\mathrm{Y}$ & $\mathrm{N}$ & Y & & 0,0 \\
\hline & & OS & 4 & & 4000 & 652 & Y & Y & 35 & - & 50 & $\mathrm{~N}$ & $\mathrm{~N}$ & $\mathrm{~N}$ & $\mathrm{~N}$ & vascularized & $\mathrm{N}$ & $\mathrm{Y}$ & & \\
\hline 15 & 21 & OD & 3 & W162X exon 7 & 200 & 668 & Y & & 35 & - & 60 & $\mathrm{~N}$ & $\mathrm{~N}$ & $\mathrm{~N}$ & $\mathrm{~N}$ & vascularized & $\mathrm{N}$ & $\mathrm{Y}$ & & 0,0 \\
\hline & & OS & 4 & & 4000 & 707 & $\mathrm{Y}$ & & 35 & - & 40 & $\mathrm{~N}$ & $\mathrm{~N}$ & $\mathrm{~N}$ & $\mathrm{~N}$ & vascularized & $\mathrm{N}$ & Y & & \\
\hline 16 & 62 & $\mathrm{OD}$ & 4 & $\mathrm{NF}$ & $\mathrm{LP}$ & 665 & & Y & 1 & - & 45 & $\mathrm{~N}$ & $\mathrm{~N}$ & $\mathrm{~N}$ & $\mathrm{~N}$ & vascularized & $\mathrm{N}$ & Y & & 0,0 \\
\hline & & OS & 4 & & 400 & 618 & Y & $\mathrm{Y}$ & 1 & - & 40 & $\mathrm{~N}$ & $\mathrm{~N}$ & $\mathrm{~N}$ & $\mathrm{~N}$ & vascularized & $\mathrm{N}$ & Y & & \\
\hline 17 & 44 & $\mathrm{OD}$ & 4 & $\mathrm{NF}$ & 400 & 520 & & Y & - & - & 50 & $\mathrm{~N}$ & $\mathrm{~N}$ & $\mathrm{~N}$ & $\mathrm{~N}$ & vascularized & $\mathrm{N}$ & Y & & 0,0 \\
\hline & & OS & 4 & & amaurosis & 800 & Y & $\mathrm{Y}$ & - & - & 45 & $\mathrm{~N}$ & $\mathrm{~N}$ & $\mathrm{~N}$ & $\mathrm{~N}$ & vascularized & $\mathrm{N}$ & Y & & \\
\hline 18 & 32 & OD & 4 & ND & 1000 & 714 & Y & & 35 & - & 25 & $\mathrm{~N}$ & $\mathrm{~N}$ & $\mathrm{~N}$ & $\mathrm{~N}$ & vascularized & $\mathrm{N}$ & Y & & 0,0 \\
\hline & & OS & 4 & & 2000 & 683 & Y & & 35 & - & 20 & $\mathrm{~N}$ & $\mathrm{~N}$ & $\mathrm{~N}$ & $\mathrm{~N}$ & vascularized & $\mathrm{N}$ & $\mathrm{Y}$ & & \\
\hline
\end{tabular}




\begin{tabular}{|c|c|c|c|c|c|c|c|c|c|c|c|c|c|c|c|c|c|c|}
\hline \multicolumn{19}{|c|}{ Control } \\
\hline \multirow[t]{2}{*}{1} & 33 & OD & 0 & ND* & 20 & 546 & - & 9 & 60 & Full & Full & Full & Full & $\mathrm{N}$ & $\mathrm{Y}$ & $\mathrm{N}$ & 5000 & 18.1 \\
\hline & & Os & 0 & & 20 & 519 & - & 9 & 60 & Full & Full & Full & Full & $\mathrm{N}$ & $\mathrm{Y}$ & $\mathrm{N}$ & & \\
\hline \multirow[t]{2}{*}{2} & 48 & OD & 0 & ND* & 20 & 483 & 12 & 8 & 60 & - & - & Partial & Partial & $\mathrm{N}$ & $\mathrm{Y}$ & $\mathrm{N}$ & 5367 & 14.3 \\
\hline & & Os & 0 & & 20 & 511 & 12 & 5 & 60 & - & - & Full & Full & $\mathrm{N}$ & $\mathrm{Y}$ & $\mathrm{N}$ & & \\
\hline \multirow[t]{2}{*}{3} & 44 & OD & 0 & $\mathrm{ND}^{*}$ & 20 & 578 & 4 & 10 & 60 & Full & Full & Partial & Full & $\mathrm{N}$ & $\mathrm{Y}$ & $\mathrm{N}$ & 5667 & 26.9 \\
\hline & & OS & 0 & & 20 & 584 & 10 & 5 & 60 & Full & Full & Partial & Full & $\mathrm{N}$ & Y & $\mathrm{N}$ & & \\
\hline \multirow[t]{2}{*}{4} & 38 & OD & 0 & ND* & 25 & 529 & 27 & - & 60 & - & - & Full & $\mathrm{N}$ & $\mathrm{N}$ & $\mathrm{Y}$ & $\mathrm{N}$ & 5233 & 16.2 \\
\hline & & Os & 0 & & 22 & 536 & 15 & 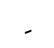 & 60 & - & - & Full & $\mathrm{N}$ & $\mathrm{N}$ & - & $\mathrm{N}$ & & \\
\hline \multirow[t]{2}{*}{5} & 42 & OD & 0 & ND* & 200 & 633 & 11 & 12 & 60 & Full & Full & Full & Full & $\mathrm{N}$ & - & $\mathrm{N}$ & 6233 & 20.5 \\
\hline & & Os & 0 & & 20 & 617 & 12 & 8 & 60 & - & - & Full & Full & $\mathrm{N}$ & $\mathrm{Y}$ & $\mathrm{N}$ & & \\
\hline \multirow[t]{2}{*}{6} & 44 & OD & 0 & $\mathrm{ND}^{*}$ & 20 & 530 & 4 & 8 & 60 & Full & Full & Full & Full & $\mathrm{N}$ & - & $\mathrm{N}$ & 5367 & 16.0 \\
\hline & & Os & 0 & & 20 & 526 & 4 & 3 & 60 & Full & Full & Full & Full & $\mathrm{N}$ & - & $\mathrm{N}$ & & \\
\hline \multirow[t]{2}{*}{7} & 45 & OD & 0 & $\mathrm{ND}^{*}$ & 20 & 531 & 20 & 15 & 60 & Full & Full & Full & Full & $\mathrm{N}$ & $\mathrm{Y}$ & $\mathrm{N}$ & 5300 & 18.2 \\
\hline & & Os & 0 & & 20 & 537 & 17 & 16 & 60 & Full & Full & Full & Full & $\mathrm{N}$ & $\mathrm{Y}$ & $\mathrm{N}$ & & \\
\hline \multirow[t]{2}{*}{8} & 50 & OD & 0 & $\mathrm{ND}^{*}$ & 20 & 533 & 12 & 8 & 60 & 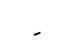 & - & - & - & $\mathrm{N}$ & Y & $\mathrm{N}$ & 5933 & 18.6 \\
\hline & & Os & 0 & & ambylopia & 537 & 8 & 9 & 60 & Full & Full & Full & Full & $\mathrm{N}$ & $\mathrm{Y}$ & $\mathrm{N}$ & & \\
\hline \multirow[t]{2}{*}{9} & 29 & OD & 0 & $\mathrm{ND}^{*}$ & 67 & 568 & 28 & 29 & 60 & Full & Full & Full & Full & $\mathrm{N}$ & - & $\mathrm{N}$ & 5100 & 15.5 \\
\hline & & Os & 0 & & 50 & 560 & 35 & 30 & 60 & Full & Full & Full & Full & $\mathrm{N}$ & Y & $\mathrm{N}$ & & \\
\hline
\end{tabular}

$\mathrm{ARK}=$ aniridia-related keratopathy; BSCVA $=$ best spectacle-corrected visual acuity; CCT $=$ central corneal thickness; $\mathrm{BUT}=$ tear break-up time test; FSP = focal stromal projection; $\mathrm{OD}=$ right eye; $\mathrm{OS}=$ left eye; $\mathrm{Y}=$ present; $\mathrm{N}=$ not present; $\mathrm{NF}=$ no mutation found; $\mathrm{ND}=$ genetic testing not done, while '*' indicates transparent corneas and iris fully present; Partial = partially present, but with abnormal morphology; Full = fully present with normal morphology; Vascularized = fully conjunctivalized epithelium with vessels present. '-' indicates that no clinical or image data was obtained. Reported subbasal nerve density values are for the central cornea.

Table 1. Clinical characteristics and IVCM parameters in aniridia patients and control subjects. 


\begin{tabular}{lcc} 
Parameter & Correlation Coefficient & P-value \\
\hline age & 0.249 & 0.313 \\
BSCVA & 0.486 & 0.040 \\
CCT & 0.452 & 0.018 \\
Schirmer & 0.365 & 0.079 \\
BUT & 0.169 & 0.480 \\
Sensitivity & -0.502 & 0.009 \\
Superior palisade ridges & -0.854 & $<0.001$ \\
Superior FSPs & -0.854 & $<0.001$ \\
Inferior palisade ridges & -0.913 & $<0.001$ \\
Inferior FSPs & -0.807 & $<0.001$ \\
Limbal nerves & -0.786 & $<0.001$ \\
Limbal inflammatory cells & 0.84 & $<0.001$ \\
Palisade cell density & -0.819 & $<0.001$ \\
Central subbasal nerve density & -0.716 & $<0.001$
\end{tabular}

Table 2. Correlation of grade of ARK with various clinical and IVCM parameters in the subject cohort shown in Table 1. Significant correlations are indicated in bold. Correlations were tested with one eye per subject (right eye) using the Spearman rank order test (see Methods). 